DE

M E D I C I N A

T R O P I C A L

$\mathrm{DE}$

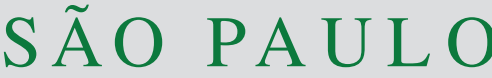

JOURNAL OF THE SÃO PAULO INSTITUTE OF TROPICAL MEDICINE

${ }^{1}$ Fundação Oswaldo Cruz (FIOCRUZ), Laboratório de Biologia e Parasitologia de Mamíferos Silvestres Reservatórios, Rio de Janeiro, Rio de Janeiro, Brazil

${ }^{2}$ Fundação Oswaldo Cruz (FIOCRUZ), Curso de Pós-Graduação em Malacologia de Vetores, Rio de Janeiro, Rio de Janeiro, Brazil

Correspondence to: Raquel O. Simões Fundação Oswaldo Cruz, Laboratório de Biologia e Parasitologia de Mamíferos Silvestres Reservatórios, Av. Brasil, 4365, CEP 21040-360, Rio de Janeiro, RJ, Brazil

E-mail: raquel83vet@gmail.com

Received: 01 August 2017

Accepted: 28 November 2017

\section{Achatina fulica infected by Angiostrongylus cantonensis on beaches, in the west zone of Rio de Janeiro, Brazil}

\author{
André H. Bechara ${ }^{1,2}$, Raquel O. Simões ${ }^{1}$, Marta Júlia Faro', Juberlan S. \\ Garcia $^{1}$
}

\section{ABSTRACT}

Angiostrongylus cantonensis is considered the main etiological agent of eosinophilic meningitis in humans. At present, this zoonosis is considered an emerging disease mainly in the Americas. The aim of this study was to determine the prevalence of Achatina fulica infected by Angiostrongylus cantonensis in restinga areas along beaches in the west zone of Rio de Janeiro city, Brazil. The study areas included the following beaches: Barra da Tijuca, Recreio dos Bandeirantes, Reserva, Prainha and Grumari. Ninety specimens of Achatina fulica were collected. Positive molluscs were found only in Barra da Tijuca. Infection prevalence was $5.5 \%$. The presence of this parasite in the beachfront areas, in the west zone of Rio de Janeiro city demonstrates the potential risk of infection for visitors and the expansion of this helminth in the State of Rio de Janeiro.

KEYWORDS: Emerging parasitosis. Eosinophilic meningoencephalitis. Giant African snail Nematode.

The nematode Angiostrongylus cantonensis (Chen, 1935) is a zoonotic parasite that causes eosinophilic meningitis, the main clinical manifestation of human angiostrongyliasis ${ }^{1,2}$. Synanthropic rats of the genus Rattus are the main definitive host $\mathrm{s}^{3,4}$ and the African snail Achatina fulica the most important intermediate host ${ }^{5-8}$. Adult worms parasitize pulmonary arteries of the definitive host, where females lay eggs that develop into first-stage $\left(\mathrm{L}_{1}\right)$ larvae ${ }^{3,9}$. These larvae move to the alveoli and pharynx and are swallowed, then eliminated in feces. Snails or slugs are infected by $\mathrm{L}_{1}$ larvae through ingestion or penetration, after which the two molts occur and the larvae become infective to definitive hosts and humans. Humans become infected by eating undercooked or raw intermediate or paratenic hosts ${ }^{3}$.

In Brazil, the first record of A. fulica naturally infected by A. cantonensis was in the municipality of Vila Velha, Espírito Santo State, and São Vicente, in São Paulo State $^{5}$. Since then, it has been reported in the municipalities of São Gonçalo, Barra do Pirai and Angra dos Reis in Rio de Janeiro State ${ }^{10,11}$, Joinville and Navegantes in Santa Catarina State ${ }^{10,11}$, Paranaguá in Paraná State ${ }^{11}$, Escada in Pernambuco State $^{7}$ and Belém, in Pará State ${ }^{12}$. According to Morassutti et al. ${ }^{13}$, in Brazil, there are intermediate and definitive hosts infected with $A$. cantonensis, however, few cases of infection have been reported. This fact could be justified by the lack of knowledge about the parasite by physicians and professionals prepared to make the diagnosis for angiostrongyliasis. The aim of this study was to determine the presence and prevalence of A. fulica naturally infected by A. cantonensis on beaches in the west zone of Rio de Janeiro city.

Between October and November 2015, A. fulica specimens were collected in 
nine points of beachfront areas in the west zone of Rio de Janeiro. Collection points coordinates were: Barra da

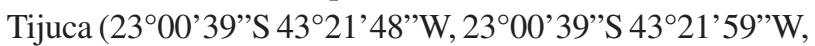
$\left.23^{\circ} 00^{\prime} 41^{\prime \prime} \mathrm{S} 43^{\circ} 22^{\prime} 15^{\prime \prime} \mathrm{W}\right)$, Recreio dos Bandeirantes

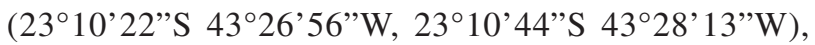

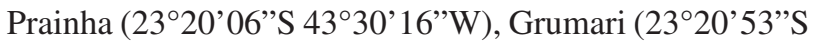
$\left.43^{\circ} 31^{\prime} 40^{\prime \prime} \mathrm{W}, 23^{\circ} 20^{\prime} 55^{\prime \prime} \mathrm{S} 43^{\circ} 31^{\prime} 38^{\prime \prime} \mathrm{W}\right)$ and Reserva $\left(23^{\circ} 10^{\prime} 20^{\prime \prime} \mathrm{S} 43^{\circ} 25^{\prime} 09^{\prime \prime} \mathrm{W}\right)$. A total of 90 snails were collected, ten per collection point. The specimens were collected manually, preferably at night or on rainy mornings. The collection was done using gloves, after which the snails were placed in plastic containers and transported in biological material boxes to the Laboratory of Biology and Parasitology of Wild Mammal Reservoirs, Oswaldo Cruz Foundation, Rio de Janeiro. The cephalopodal masses of molluscs were individually fragmented and $\mathrm{L}_{3}$ larvae were obtained according to Garcia et al. ${ }^{14}$. The number of larvae recovered was expressed as mean \pm standard deviation.

After counting of $\mathrm{L}_{3}$ larvae, three Wistar rats were infected with 60 larvae each through an orogastric probe (Medsonda, $5 \mathrm{~mm}$ ) and kept in a vivarium to confirm the infection by A. cantonensis. All procedures were approved by the Animal Experimentation Ethics Committee of the Oswaldo Cruz Foundation (LW-47/14). Adult nematodes were recovered 40 days after infection in the pulmonary arteries of the rodents and their morphology was identified according to Anderson et al. ${ }^{15}$ and Maldonado et al. ${ }^{10}$.

Five A. fulica were infected by A. cantonensis in Barra da Tijuca with a prevalence of 5.5\% (5/90). The mean intensity of $\mathrm{L}_{3}$ recovery was $183( \pm 238)$ per infected snail. Twenty-one, 31 and 39 adult worms of $A$. cantonenis with a total of 58 males and 33 females were recovered in the three infected rats, respectively. In males, specific morphological characteristics as the caudal bursa and the spicule length were observed confirming the identification of helminth specimens as A. cantonensis.

Human angiostrongyliasis is an acute disease caused by $A$. cantonensis that affects the central nervous system. This infection was previously restricted to Asia and the Pacific islands mainly due to food and cultural habits of these populations ${ }^{16}$. However, the rapid spread of A. fulica in different countries around the world has contributed to the dispersion of the nematode and consequently the zoonosis ${ }^{11,17}$. In Brazil, intermediate and definitive hosts infected with $A$. cantonensis have been identified in urban areas of several Brazilian states, including those in the North, Northeast, Southeast and South regions ${ }^{13}$. Recent studies carried out in the municipality of São Gonçalo, Rio de Janeiro State, showed that $R$. norvegicus, A. fulica and $B$. similaris are the main definitive and intermediate hosts of A. cantonensis $^{18,19}$, playing important roles in the transmission dynamics of this nematode, since they presented high abundance and high infection rates in various studies.

Infected molluscs were found exactly in the most anthropic areas of the study, where presence of trash left by beachgoers, garbage from food kiosks and rats was observed. This plentiful food availability contributes to the presence of both intermediate and definitive hosts, thus favoring the life cycle of the parasite, as also observed by Simões et $a l .{ }^{4}$. The prevalence of the nematode in the intermediate host was low, differing from the results reported by Oliveira et al. ${ }^{19}$ that observed a prevalence of $78.7 \%$ in A. fulica infected by A. cantonensis. The rate of helminth recovery after the experimental infection corroborates with the results obtained by Garcia et al. ${ }^{14}$, who observed a variation of $25-51 \%$.

From these results, it is possible to conclude that the presence of A. fulica naturally infected by A. cantonensis along the beachfront areas of Barra da Tijuca should serve as an alert to public health authorities of the potential risk of infection to visitors, especially children. Moreover, the presence of this helminth along the beaches of the west zone of the Rio de Janeiro demonstrates the expansion of this nematode in the State of Rio de Janeiro.

\section{ACKNOWLEDGMENTS}

ROS and JSG received financial support from FAPERJ (Fundação de Amparo à Pesquisa do Estado do Rio de Janeiro).

\section{REFERENCES}

1. Lima AR, Mesquita SD, Santos SS, Aquino ER, Rosa LR, Duarte FS, et al. Alicata disease: neuroinfestation by Angiostrongylus cantonensis in Recife, Pernambuco, Brazil. Arq Neuropsiquiat. 2009;67:1093-6.

2. Luessi F, Sollors J, Torzewski M, Müller HD, Siegel E, Blum J, et al. Eosinophilic meningitis due to Angiostrongylus cantonensis in Germany. J Travel Med. 2009;16:292-4.

3. Maldonado Jr A, Simões R, Thiengo S. Angiostrongyliasis in the Americas. In: Lorenzo-Morales J, editor. Zoonosis. Rijeka: InTech; 2012. p.303-20.

4. Simões RO, Maldonado Jr A, Olifiers N, Garcia JS, Bertolino AV, Luque JL. A longitudinal study of Angiostrongylus cantonensis in an urban population of Rattus norvegicus in Brazil: the influences of seasonality and host features on the pattern of infection. Parasit Vectors. 2014;7:100.

5. Caldeira RL, Mendonça CL, Goveia CO, Lenzi HL, GraeffTexeira C, Lima WS, et al. First record of molluscs naturally infected with Angiostrongylus cantonensis (Chen, 1935) 
(Nematoda: Metastrongylidae) in Brazil. Mem Inst Oswaldo Cruz. 2007;102:887-9.

6. Graeff-Teixeira C. Expansion of Achatina fulica in Brazil and potential increased risk for angiostrongyliasis. Trans R Soc Trop Med Hyg. 2007;101:743-4.

7. Thiengo SC, Maldonado A, Mota EM, Torres EJ, Caldeira R, Carvalho OS, et al. The giant african snail Achatina fulica as natural intermediate host of Angiostrongylus cantonensis in Pernambuco, Northeast Brazil. Acta Trop. 2010;115:194-9.

8. Iwanowicz DD, Sanders LR, Schill WB, Xayavong MV, Silva AJ, Qvarnstrom Y, et al. Spread of the rat lungworm (Angiostrongylus cantonensis) in giant African land snails (Lissachatina fulica) in Florida, USA. J Wild Dis. 2015;51:74953.

9. Yousif F, Lämmler G. The mode of infection with and the distribuition of Angionstrongylus cantonensis larvae in the experimental intermediate host Biomphalaria glabrata. Z Parasitenkd. 1977;53:247-50.

10. Maldonado J A, Simões RO, Oliveira AP, Motta EM, Fernandez MA, Pereira ZM, et al. First report of Angiostrongylus cantonensis (Nematode: Metastrongylidae) in Achatina fulica (Mollusca: Gastropoda) from Southeast and South Brazil. Mem Inst Oswaldo Cruz. 2010;105:938-41.

11. Carvalho OS, Scholte RG, Mendonça CL, Passos LK, Caldeira RL. Angiostrongylus cantonensis (Nematoda: Metastrongylidae) in molluscs from harbour areas in Brazil. Mem Inst Oswaldo Cruz. 2012:107:740-6.

12. Moreira VL, Giese EG, Melo FT, Simões RO, Thiengo SC, Maldonado Jr A, et al. Endemic angiostrongyliasis in Brazilian Amazon: natural parasitism of Angiostrongylus cantonensis in Rattus rattus and R. norvegicus, and sympatric giant African land snails, Achatina fulica. Acta Trop. 2013;125:90-7.
13. Morassutti AL, Thiengo SC, Fernandez M, Sawanyawisuth K, Graeff-Teixeira C. Eosinophilic meningitis caused by Angiostrongylus cantonensis: an emergent disease in Brazil. Mem Inst Oswaldo Cruz. 2014;109:399-407.

14. Garcia JS, Bonfim TC, Maldonado Jr A., Tunholi VM, Tunholi-Alves VM, Mota EM, et al. Hematological and histopathological changes in Rattus norvegicus (Wistar) experimentally infected by Angiostrongylus cantonensis (Chen, 1935). Parasitol Int. 2014;63:631-7.

15. Anderson RC, Chabaud AG, Willmott S, editors. Keys to the nematode parasites of vertebrates: archival volume. Wallingford: CABI; 2009.

16. Wang QP, Lai DH, Zhu XQ, Chen XG, Lun, ZR. Human angiostrongyliasis. Lancet Infect Dis. 2008;8:621-30.

17. Kliks MM, Palumbo NE. Eosinophilic meningitis beyond the Pacific Basin: the global dispersal of a peridomestic zoonosis caused by Angiostrongylus cantonensis, the nematode lungworm of rats. Soc Sci Med. 1992;34:199-212.

18. Simões RO, Monteiro FA, Sánchez E, Thiengo SC, Garcia JS, Costa-Neto SF, et al. Endemic angiostrongyliasis, Rio de Janeiro, Brazil. Emerg Infect Dis. 2011;17:1331-3.

19. Oliveira AP, Gentile R, Maldonado Jr A, Torres EJ, Thiengo $\mathrm{SC}$. Angiostrongylus cantonensis infection in molluscs in the municipality of São Gonçalo, a metropolitan area of Rio de Janeiro, Brazil: role of the invasive species Achatina fulica in parasite transmission dynamics. Mem Inst Oswaldo Cruz. 2015;110:739-44. 